\title{
Construction of geodesic domes made of wood and composite materials during restoration and conservation of cultural heritage objects
}

\author{
Dmitry Zhivotov ${ }^{1, *}$, and Olga Pastukh ${ }^{1}$ \\ ${ }^{1}$ Saint Petersburg State University of Architecture and Civil Engineering, 190005, 2-nd \\ Krasnoarmeiskaia St. 4, St. Petersburg, Russia
}

\begin{abstract}
The paper provides an overview of the existing structural and technological solutions for the construction of outdoor shelters over cultural heritage objects during restoration works in order to preserve from environmental influences and prevent external precipitation from entering buildings and structures. For these purposes, it is proposed to use standard solutions for various spans in the form of geodetic dome structures to protect buildings and structures from external precipitation and other atmospheric phenomena. The paper highlights the authors' work on the creation of new technical solutions for geodesic domes made of wood and high-strength polymers, which will significantly facilitate load-bearing structures, compared to metal and reinforced concrete. Also, the use of modern materials and technologies for the construction of protective structures will allow taking care of the environment, taking into account GREEN and ZOOM standards.
\end{abstract}

\section{Introduction}

Preservation of cultural heritage object is research, survey, design and production works, including the complex of emergency protection of the cultural heritage object, which is threatened by the rapid destruction, those carried out in order to prevent the deterioration of the state of the specified cultural heritage object without having changed its present appearance reached to date and having kept safe the subject of protection of the cultural heritage object, according to article 41 of the Federal law of the Russian Federation on 25.06.2002 N 73-FZ [1].

When required, on the basis of the report on the technical condition (technical condition report) of the cultural heritage object or preliminary engineering conclusion, as part of the preliminary work, there is being developed a project plan for emergency and conservation priority actions, including an explanatory note, a working documentation, object and local estimates [2]. The works that are provided for by the conservation project are carried out in order to prevent further destruction of the building under the influence of atmospheric precipitation. That is why the issue of carrying out of this type of work under the protection

\footnotetext{
* Corresponding author: d.zhivotov@mail.ru
} 
of external shelters over cultural heritage objects is particularly relevant. Existing structural and technological solutions for erecting outdoor shelters over cultural heritage objects during restoration works and facilities, with the aim of preserving from environmental influences and preventing external precipitation from entering buildings and structures, can be supplemented and improved using new technical solutions for geodesic domes of wood and high-strength polymers. This will not only significantly facilitate the load-bearing structures, compared to metal and reinforced concrete, but also provide an opportunity to take care of the environment, taking into account European GREEN and Russian ZOOM standards.

\section{Methods}

\section{Overview of the existing structural and technological solutions for erecting of external shelters over cultural heritage objects}

In areas with heavy precipitation, the following types of shelters are widely used in practice:

1.1. Construction of the structure around the building from various types of scaffolding, sheathed with edged sawn timber, followed by laying of a plastic film (in common use this structure is called "teplyak") for work in the winter season (Fig. 1).

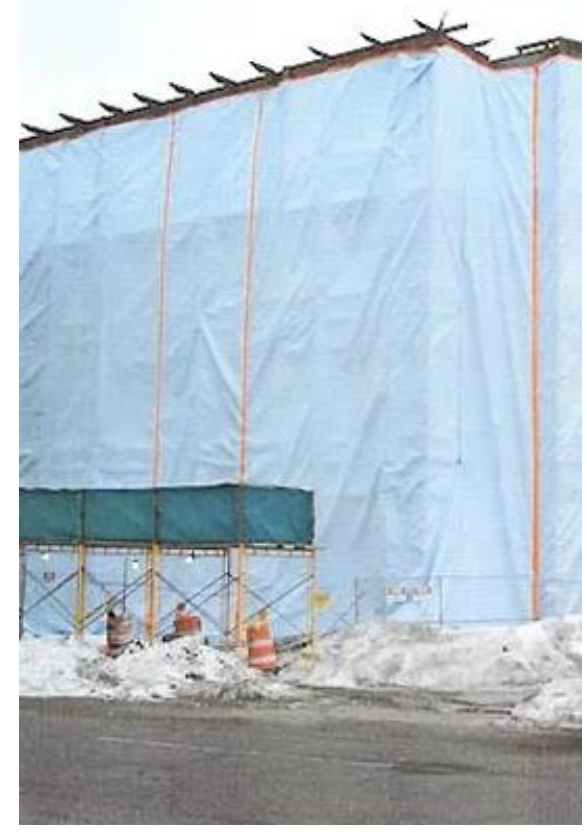

Fig.1. Closed-up facades of building for period of object restoration or conservation.

1.2. Installation of canopies or other shelters over open structures of buildings or facilities, over places of archaeological excavations (Figure 2a, b). 
a

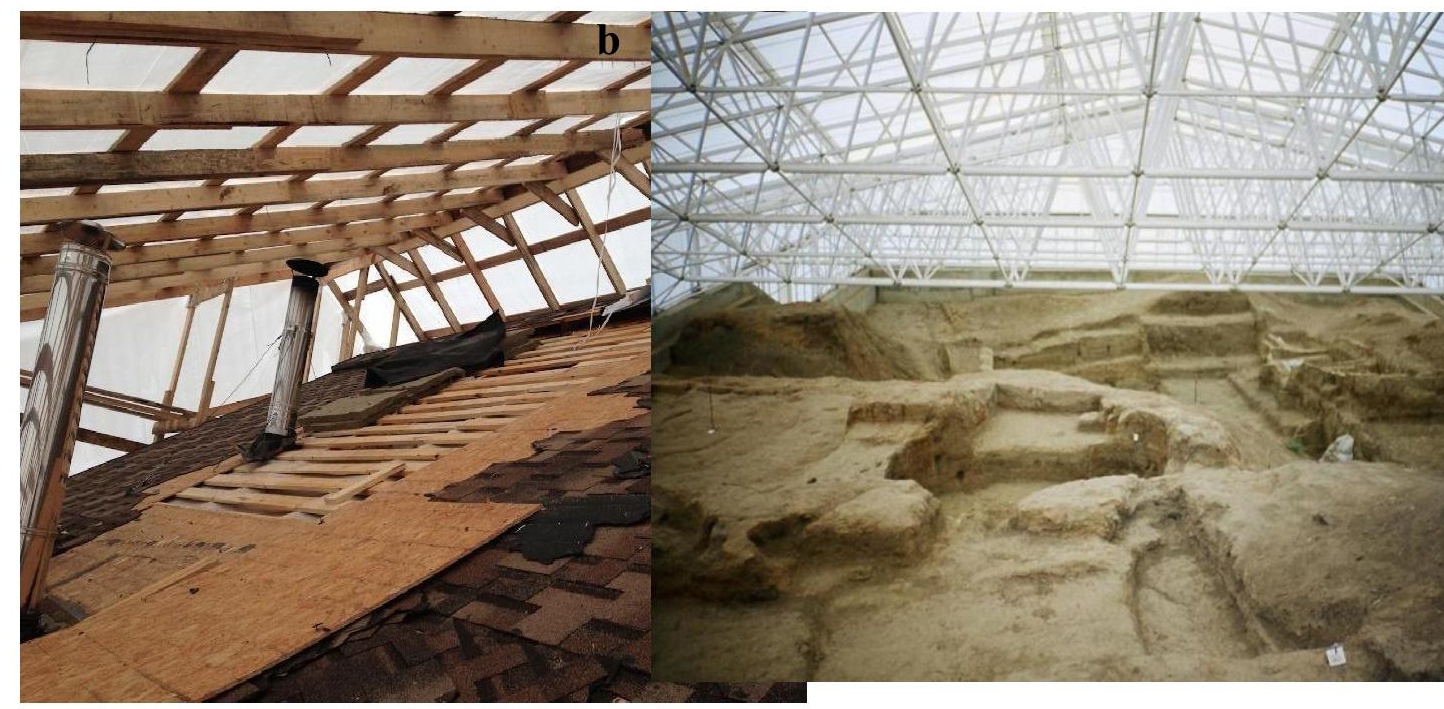

a - temporary roof over building or facility

https://intellect-profstroy.com/vremennaya-krovlya-iz-plenki/;

b - temporary structure over archaeological research area

http://sdelbiombo.blogia.com/2010/021601-la-primera-ciudad-de-la-historia.-catal-huyuk.php

Fig. 2. Options of technical solutions for temporary roofing.

Thus, when required to exclude atmospheric precipitation in places of archaeological work, objects without a roof, window and door fillings, it is proposed to use standard designs of geodetic domes in the process of restoration work. Placement of such types of structures is advisable and justified both in terms of construction and financially and economically. Important factors are indicators such as: speed and ease of installation and dismantling, labor costs and qualification of workers. Application of structures of such kind is proposed in an open area, where there is no infill development and other factors affecting the technical and technological processes of installation of geodesic domes.

\section{Results}

\section{Prerequisites for creating economically promising solutions from wood and composite materials}

3.1. The history of the construction of the geodesic dome began in 1951 with a patented solution by American inventor Richard Buckminster Fuller. The design proposed by the engineer covered the most possible space, using the minimum volume of building materials. The most interesting fact is that the larger the span covered by the dome, proportional to the change in its size, the easier and more reliable its spatial rigidity and design. [3]

3.2. The real structure of the geodesic dome consists of pieces of wooden beams, metal rods, plastic tubes, accurate lengths and connected to each other in nodal joints.

The main advantages of geodesic domes are:

large bearing capacity;

any spans from 24 to 150 meters; 
fast installation speed compared to traditional frame and frameless methods of building construction;

the weight of the dome elements reduces the cost of materials and work of the zero cycle;

structural and technological features of spatial dome structures is the installation of frame elements from marked rods and nodes, which reduces the construction time. The cellular structure will allow the assembly of blocks of cells, which will significantly reduce the construction time of the building [4];

spatial dome structures have an ideal aerodynamic shape with high resistance to seismic, wind and hurricane impacts. Scientists continue to study the possibility of using geodesic domes by changing its shape, configuration, manufacturing material and many other parameters [5].

cellular configuration of many of the available Diamatic dome templates is particularly convenient for conversion with mutual element support. This is due to the fact that at any vertex only three elements of the lattice rods intersect, regardless of the number of rod elements used to form the polygon of the node [6].

3.3. The disadvantages of geodesic domes include the fact that the production of modern building materials is aimed primarily at the construction of buildings made of rectangular materials (plywood, glass, hard insulation mats). Thus, triangular cells of geodesic domes will require additional labor to trim and fit the material to create external enclosing structures with a large overspend, increasing the cost and complexity of manufacturing the building as a whole [7].

3.4. Known schemes prove the statement about the complexity of nodal connectors, their low technological efficiency of installation, high complexity and material consumption of products. Nodal connectors are steel, regardless of the material of rods (Figure $3 \mathrm{a}, \mathrm{b}$ ).

a

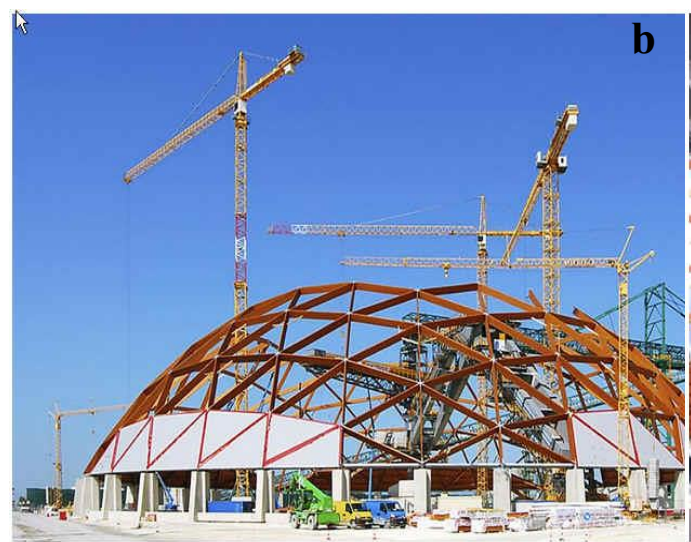

a - general scheme of installation.

https://structurae.net/de/produkte-services/groesste-holzkuppel-europas;

b - applied technological equipment and accessories

https://structurae.net/de/produkte-services/groesste-holzkuppel-europas

Fig. 3. General view of real objects.

3.5. The authors of this paper make an assumption about the possibility of using the dome space to preserve cultural heritage objects, both during restoration and adapting works, as well as during museumification. As an example, we can talk about the project of creating a museum exposition in the workshops of the Vuksunsky Metallurgical Plant in the city of Vyksa (1897, V. Shukhov), by constructing a geodesic dome over the building. The 
authors propose their ideas for consideration, based on existing experience in creating space above a residential building in Sweden [8] and in Yakutia at a temperature of 70 degrees Celsius [9].

In Figure 4, you can see the idea of creating a living space under the dome [10].

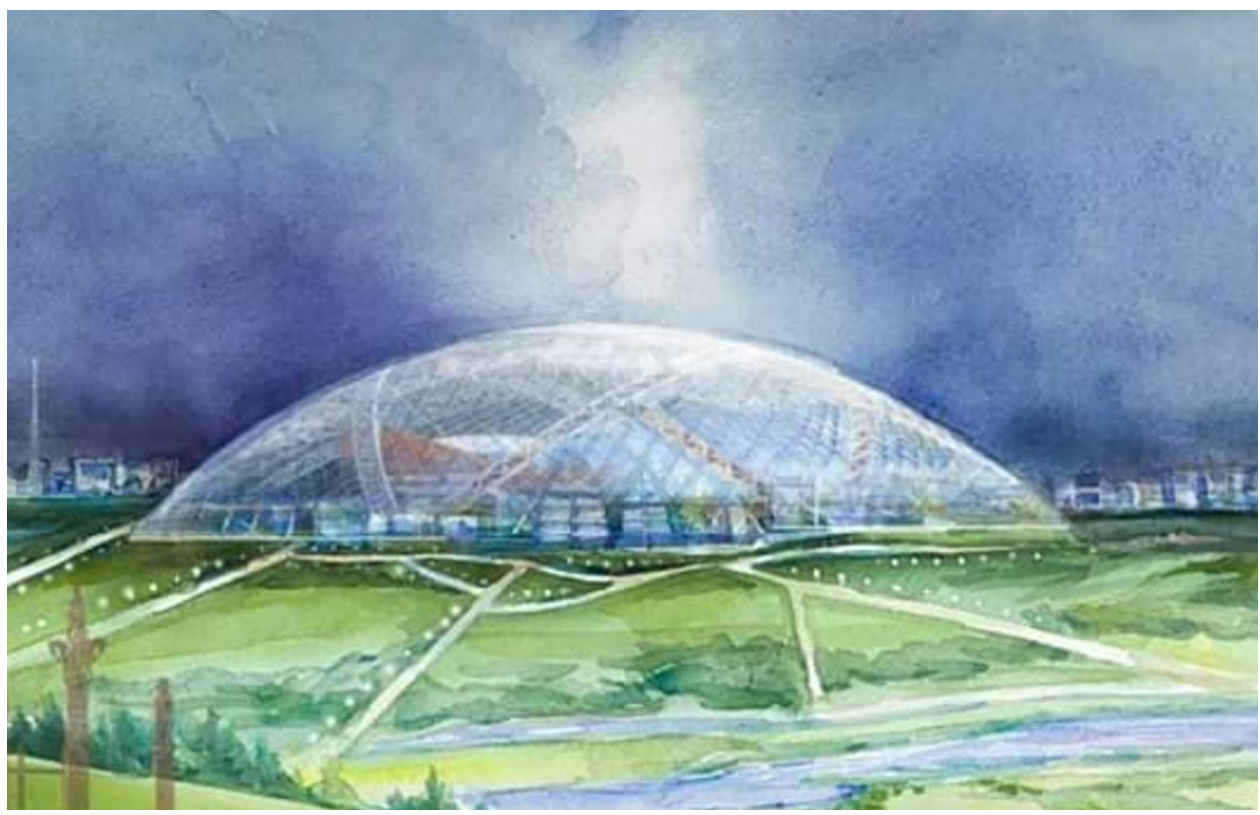

https://m.facebook.com/kyydaana.ignateva

Fig. 4. Geodesic dome over residential areas.

This issue has already been raised by undergraduates of the St. Petersburg State University of Architecture and Civil Engineering. In particular, in 2018, in his final qualifying work, undergraduate Ayat Alnajar proposed solutions for the installing of enclosing structures over historic buildings and facilities, using the example of preservation of cultural heritage objects in Jordan. 


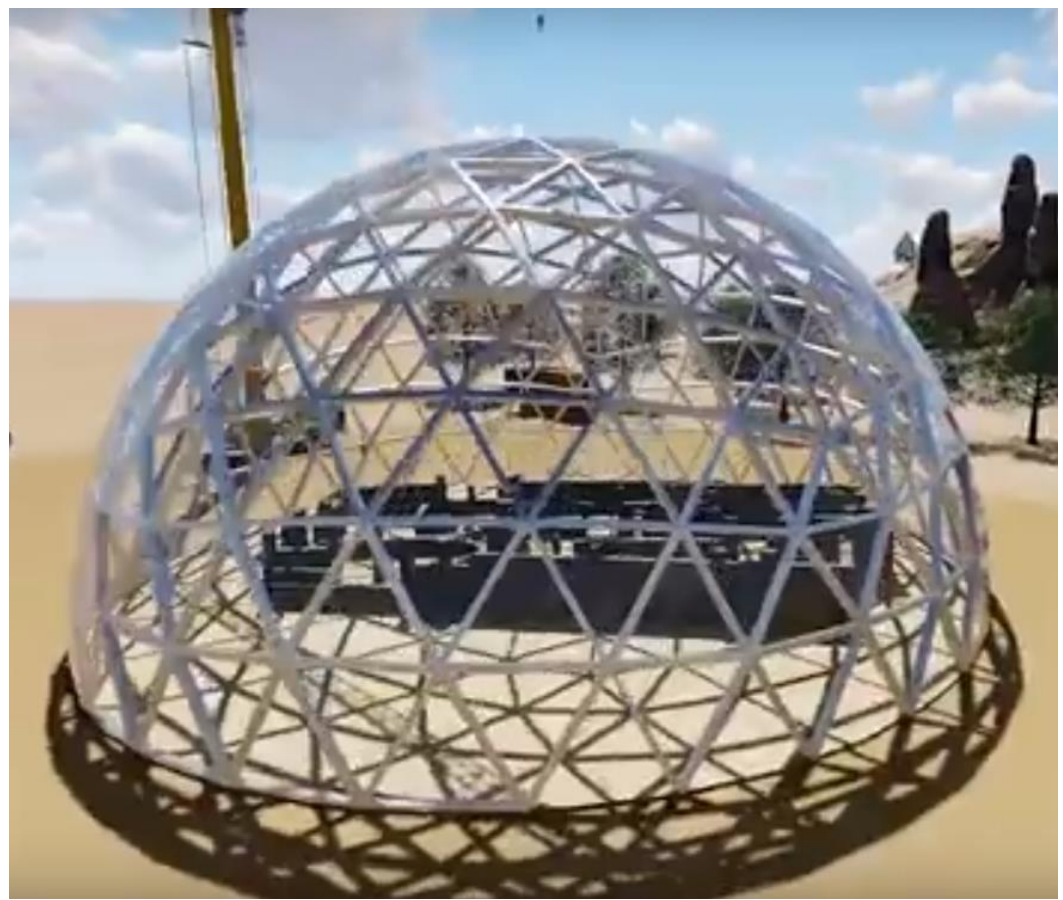

https://www.spbgasu.ru/en/For_Prospective_Students/The_invitation_for_studying_at_St._Petersburg_State_Univ ersity_of_Architecture_and_Civil_Engineering/

Fig. 5. Fragment of master's thesis by Ayat Alnajar 2018.

3.6. The authors highlight the following positive aspects of this technical solution during archaeological work and restoration of cultural heritage objects:

1. The absence of atmospheric precipitation in the work zone;

2. Creating a favorable microclimate for the object of cultural heritage and restorers in the process of work performance;

3. Free movement and execution of technological operations in the area of work;

4. The ability to perform work at any time of the year on a 24-hour basis and 7 days a week;

5. It will reduce the risk of failure to meet the deadlines for the production of works;

6 . Will improve the quality of restoration work.

The design of the geodesic dome since its inception in the middle of the 20th century has not changed significantly and the semantic load remains the same: to cover as much space as possible using the minimum amount of building materials, while maintaining lightness and reliable spatial rigidity. The material of the structures is changing. Instead of heavyweight reinforced concrete and metal, it is proposed to build domes of glued wood and high-strength polymers. The coating material of the geodesic domes may be different. Starting from windows made of wooden frames and single-layer glass, and ending with insulated panels of various thicknesses, depending on the area where such a structure is located. The only thing that combines all these technical solutions and products is a triangular shape, which completely repeats the outline of the load-bearing elements of this building. The authors of this paper propose to dwell on several materials for the manufacture of these panels, depending on the region of construction, temperature and humidity conditions under the dome during the production process and the need for insolation and artificial lighting. 
3.7. Scientific theorists and practitioners around the world continue their research into the field of obtaining renewable energy from natural sources. Using the surface of the geodesic dome is an excellent solution to this problem [11].

The authors of the paper conduct research on the design and technological features of the new nodal connection using wood in the form of rods and high-strength polymers in nodal connections in specialized laboratories of SPbGASU. In 2017, a patent was obtained for a utility model for a node for geodesic domes and other facilities RU No. 170483 [12].

\section{Discussion}

The environmental situation in the world over the past decades has changed significantly not for the better. The occurring natural disasters are forcing mankind to think about the need to reduce $\mathrm{CO} 2$ emissions, to create technical solutions aimed at using natural materials with a minimum amount of waste in the process of their production. Such building materials are considered to be wood and materials based on it. This is a constantly renewable resource that is easy to process and does not leave after the use of inorganic substances.

Polymer materials are interesting in both technical and physical-mechanical properties. A wide range of properties of these materials, changing with the help of various manufacturing methods, opens up a ton of opportunities for scientific and scientifictechnical solutions in the future.

In modern practice, solutions for the manufacture of geodesic domes from metal and reinforced concrete structures are widely used. However, the authors of the paper believe that the combination of wood and polymeric materials in the design of geodesic domes is the most advantageous combination in all areas: engineering, financial, economic, energy and even environmental.

The authors build up their own opinion not only on the study of existing experience in building and using geodesic domes in various fields of construction, but also based on their own experimental studies of the nodal dome joint by applying various loads, in order to simulate real processes while the structure operation and to determine actual performance bearing capacity of nodes and elements.

These tests were carried out on specialized equipment in the mechanical laboratory of $\mathrm{SPbGASU}$ at a normal temperature of $220 \mathrm{C}$ (Fig. 5a, b). 
a

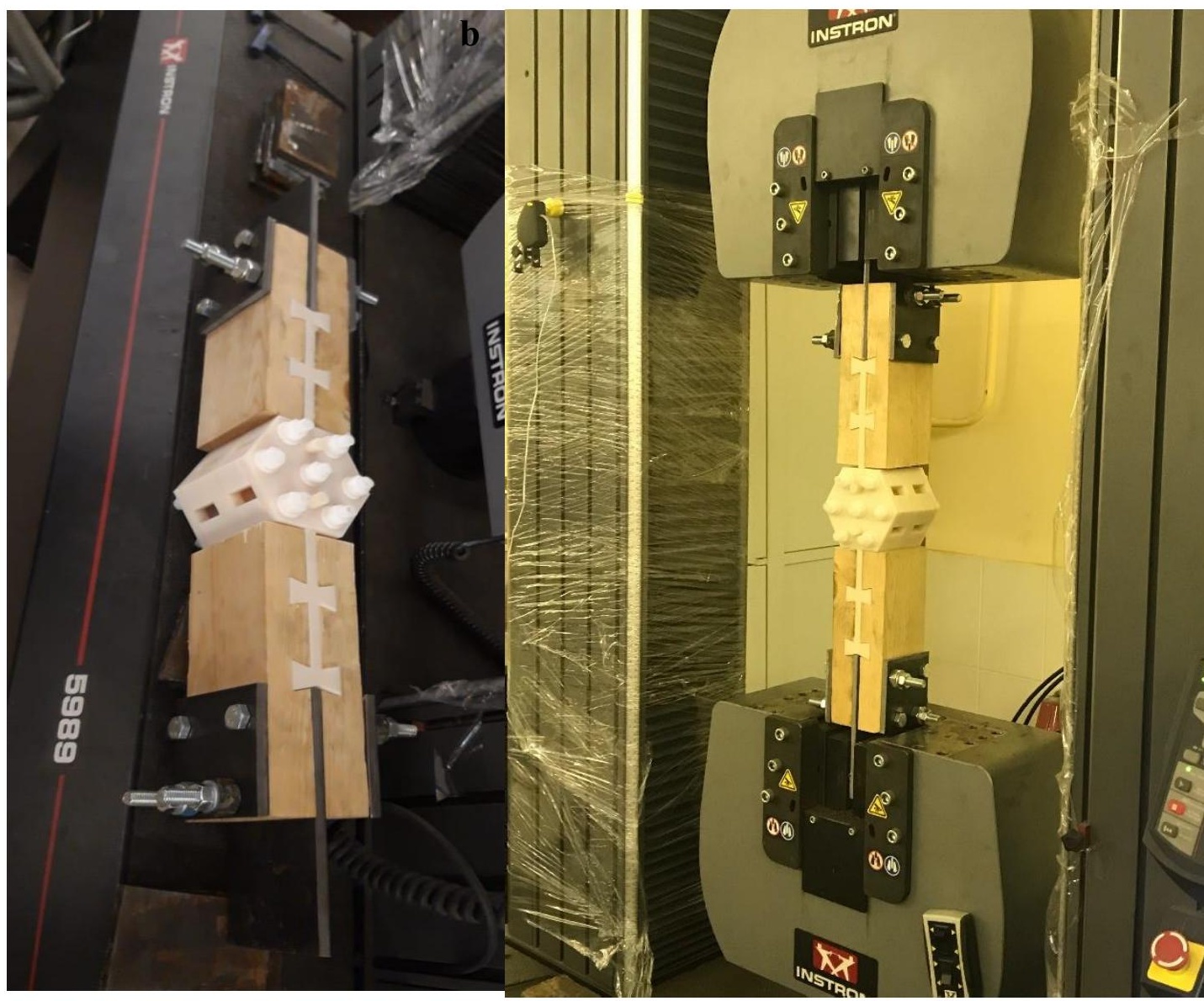

Figure 5. Photos by D.A. Zhivotov: a - assembly; b-joint test by the Intron 5998 machine.

\section{Conclusions}

1. Erecting of geodesic domes made of wood and composite materials over cultural heritage objects will create favorable conditions for their preservation, conservation and restoration work in any weather conditions.

2. Conducted experimental studies of the nodal connection showed the viability of the proposed structural and technological scheme. During the experiment, the behavior of individual elements and the design of the assembly as a whole was examined. Bearing capacity of the nodes in experimental studies corresponded to the calculated values.

3. Technical solution for creating a geodesic dome in the form of a protective shield over cultural heritage objects will slow down the process of their destruction, will improve the quality of restoration work, reduce the risk of poor-quality work, and will allow the restoration of an object of any complexity in any weather conditions.

\section{References}

1. Federal law of 06.25.2002 N 73-FZ (as amended on 07/18/2019) "On objects of cultural heritage (historical and cultural monuments) of peoples of Russian Federation" 
2. GOST R 55528-2013. Composition and content of scientific and design documentation for preservation of cultural heritage objects. Monuments of history and culture. General requirements

3. R. Fuller, Geodesic domes. https://ongreenway.org/2014/12/geosfera-fullerageodezicheskij-kupo/

4. Y. Wu, M. Takatsuka. Neural Networks 19, 900-910 (2006). DOI: 10.1016 / j.neunet.2006.05.021

5. Y. Guan, L. N. Virgin, D. Helm, Journal of Solids and Structures 155, 225-239 (2018). DOI: 10.1016 / j.ijsolstr.2018.07.022

6. J.P. Rizzuto, Engineering Structures 166, 496-510 (2018). DOI: 10.1016 / j.engstruct.2018.03.094

7. D.A. Zhivotov, V.V. Latuta, materials of 75 th scientific conference of professors, teachers, researchers, engineers and graduate students, St. Petersburg University of Architecture and Civil Engineering, 231-237

8. House under glass in Sweden. https://www.forumhouse.ru/articles/other/4885

9. First experimental dome in Yakutsk. https://fullerdome.com/dom-pod-kupolom-vyakutske

10. K. Ignatiev, Architectural works. https://m.facebook.com/kyydaana.ignateva

11. M.A. Porta-Gándara, V. Gómez-Muñoz. Energy 30, 2474-2486 (2005). DOI: 10.1016 / j.energy.2004.12.001

12. 12. V.I. Bushin, D.A. Zhivotov, Connection of load-bearing rods for geodesic domes and other spatial structures, Patent No. RU170483U1 (Moscow, Russia). 